\title{
Planning a Design Course for Play Experience and FabLab
}

\author{
Chien-Kuo Teng ${ }^{1, *}$, Ming-Chuen Chuang ${ }^{1}$, Chun-Cheng Hsu ${ }^{2}$ \\ ${ }^{1}$ Institute of Applied Arts, National Chiao Tung University, Taiwan \\ ${ }^{2}$ Department of Communication \& Technology, National Chiao Tung University, Taiwan
}

Copyright $(\subset 2015$ by authors, all rights reserved. Authors agree that this article remains permanently open access under the terms of the Creative Commons Attribution License 4.0 International License

\begin{abstract}
With the current popularity and widespread use of high-tech and telecommunication products, digital information with varied forms of software, hardware, and multimedia was engaged in designs for entertainment and daily life; its related products are sweeping the globe. On the other hand, the rapid development of 3D printing technology further caused a boom of FabLab. To develop designs with strong and rich experiences a designer must be able to fully understand user-experience. This study will present the thinking of planning a new course with integration of Play, Sci-Fi \& Design to share how such course attempt to provide students with learning motives via approaches of play and scenario, and to establish a degree of fun in the learning environment, in order to motivate students to identify the blind spots in the existed situation and to take challenge to learning new experience more directly through participation and interaction in play. This was done by breaking down the barriers between play experience and rapid prototype design of Fab Lab. Based on this thinking the course structure and content was planned and presented in this paper.
\end{abstract}

Keywords Design Course, Play Experience, FabLab, Sci-Fi, Prototype

\section{Introduction}

In order to close the gap between theory and reality, design courses in the past usually emphasized "learning by doing". With the current popularity and widespread use of high-tech and telecommunication products, digital information with varied forms of software, hardware, and multimedia was engaged in designs for entertainment and daily life. Related products are sweeping the globe, and become part of the daily life for consumers, which also further heightened their dependency on IT products. The concept of Fabrication Laboratories (FabLabs) was established by Neil Gershenfeld(2005) at the Massachusetts Institute of Technology (Tanaka, 2012; Posch \& Fitzpatrick,
2012; Kohtala \& Bosque, 2014). That was open the possibilities for engaging in the production of technologies directly and the opportunity to share information, resources within the FabLab network. Recently, Posch \& Fitzpatrick(2012) was mention that first steps in the FabLab and its experiences engaging children, that was studies with $3 \mathrm{D}$ printing and $3 \mathrm{D}$ creation for children aged 10 to 14 years old. It would make something change at education and experience of play. In order to impress consumers, to allow users to escape the confines of reality and just enjoy the pure sense of satisfaction in play, developers for toys and games must first understand the experiences of the users and look for issues of their concerns. Norman(2004) indicated that an object must be rich and complicated, so its constituent elements can create endless interactions. In order to establish an object-user relationship through the object of design, a designer needs two abilities: the ability of creating a strong and rich object-experience and the ability of understanding user-experience. To a new product especially, before going into manufacturing and selling stages, related user-experience must be first discussed. The secret to achieve a successful object-user relationship is "seduction." In order to seduce the consumers, story and process must also be paid attention to. Rodgers \& Milton once asked Nendo regarding the skills he employed in developing product concepts, and Nendo replied, "There are a lot of aspects that we must decide, but the story behind the case is the most important one. We never say we are designing a product, but designing a story. The story is everything that is born from the product." On the other hand, process is also an important factor. Kotler \& Rath (1990) pointed out that design is the process of seeking to optimize consumer satisfaction and company profitability through the creative use of major design element. Bruce \&Bessant (2002) also mentioned a British Standard for the process; in essence there are three broad phases of activity: a planning phase, development phase, production and sales phase.

This study believes that play takes an important role in current product designs, therefore planning design course for next generation must take into account both the logics in 
design thinking and imaginations in play experience. Brown (2010) believes that for design thinking to successfully work, it must fully integrate insight, observation and empathy to turn "requirements" into "demands." Looking from another angle, the integration of these three elements requires the emotion investment of the designers, so the designers can see, experience, to be in the other person's shoe, and to discover opportunities for designs. Suri\& Marsh (2000) used cases of IDEO as examples and suggested the "scenario building" method to assist designers in developing a scenario building mode of interchangeable virtual characters and story scenarios. It can be used as a tool of communication and a prototype of exploration which helps designers in depiction and evaluation of the design process during the initial stages of product concept development. More importantly, it can increase the opportunity to visualize the concept, improve the quality of interactive experience among the users, potential product, and the system, and also utilize a "make real" method to support teams of different fields to understand the situation and overall context before confirming a direction of development. This method creates a series of modes with different demographic casts of characters to depict the operations of real activities, which allow the designer to better grasp the demands of the users and to better response to new technology. Game design was also created a new world to make attraction for new environments. According to Innocent (2004) identifies the model with five key principles: space, language/ culture, experience design, logic and behavior. On the aspect of design development, in order to look for design opportunities, Battarbee (2001) also used a scenario building method in creating and sharing of experiences, such as recalling a scenario that happened in the "past," or representing a virtual experience of the "future." It was a challenge by designer that transform with play experience become a real object from scenario and virtual worlds.

\section{The Connection between Play and Digital Fabrication}

Though the technological advancements have been rapid, there are still no defined methods for assisting designers to motivate the consumers, and to let consumers generate fun in using the product. The renowned Media Lab of MIT, embracing the "demo or die" philosophy, provided the diverse workshop activities and inspired Hackathon (hacker + marathon) spirit for their students, to encourage them actively exhibit their works, seek for a cross-industry integration of digital technology, information, and arts in a diverse way, and lead the technological imaginations of the public and the industry. Regarding the study on play, Benyon $\&$ Turner (2005) suggested the concept of Infotainment. The word "infotainment" is combined from the words "information" and "entertainment" as integration of two behaviors and concepts, and also as a classic example of the integration of traditional behavior and technology.

Due to the rapid evolution of manufacturing technology, early devices of numerical controls such as CNC (Computerized Numerical Control) or CAM (Computer Aided Manufacturing), have become lightweight and compact, such as the Fabricator (a 3D printer) that fits on a desktop. The rapid development of 3D Printing technology caused a boom in Fab Lab trends, and this "just do it" trait of spontaneity in manufacturing brings diverse possibilities. Tanaka (2012) mentioned that "evolved from digital fabrication, the Fab Labs have also begun to spread among the profession design communities." Creative designers in product, furniture, fashion, architecture design fields have gradually started to explore the application of this kind of desktop digital fabrication technology. On the other hand, the 3D simulation technology in the gaming and cinema industries further promoted the trends of digital communication and learning in amusement and play experiences.

\subsection{The Thinking Structure of Planning a New Design Course with Play, Sci-Fi \& FabLab}

Overall, this course emphasizes "experience through play," and is constructed upon the base of play and scenario. Out of which, it is established by the integration of play and toy, and pleasure and adventurous excitement. Enjoyment sits at the cross core of these four elements, as illustrated in Figure 1, and scenario is a connecting bridge between function, technology and user-experience. It is also through technology that 3D Printing, sensor, RC (Remote Control), VR (Virtual Reality), and manufacture are all connected. During the creating process of scenario and user-experience, the relationship between status, situation, and sensation must also be considered. To complete the thinking structure of this course we suggest to include the 5 critical components of the play spirit: survival challenge (facing with what kinds of pressure to survive), competitiveness (what kind of rewards or punishments would yield from the score), sociability (making friends while playing), dexterity (dexterity of operation), and medium (what kind of method to experience play), as shown in the horizontal dimension of Fig.1. 


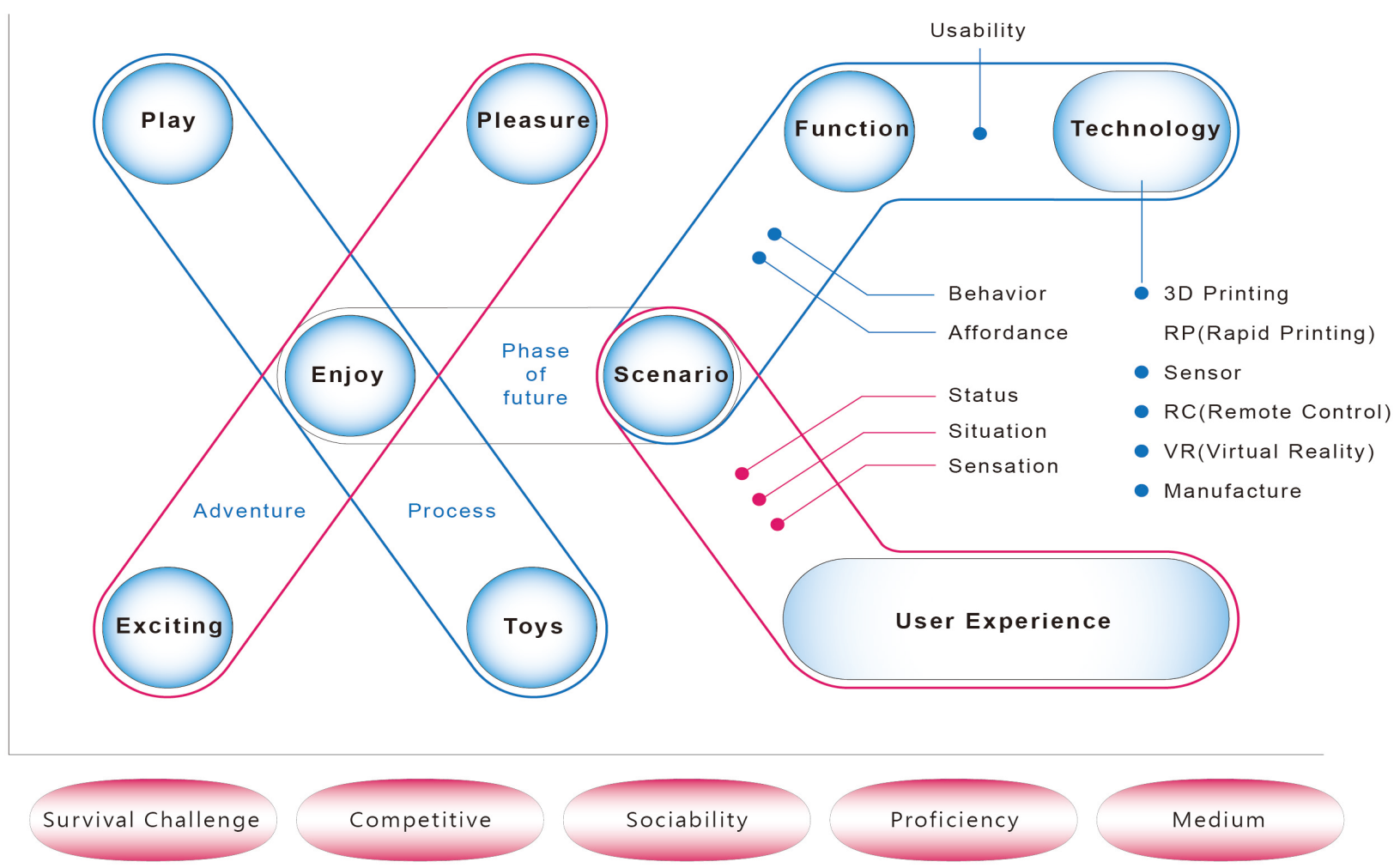

Figure 1. The concept of Thinking Structure for Course Planning

\subsection{Activity Planning of the New Design Course}

Based on the said background, this course attempts to establish a learning environment with fun for design students, via approaches of play and scenario, in order to motivate students to identify the blind spots in the existed situation and to take challenge to learning new experience more directly through participation and interaction in play. This course is held 3 hours weekly in the fall semester of 2014 in the Institute of Applied Arts (IAA) of the National Chiao Tung University (NTU) of Taiwan. There are 12students participated in this course, including 9 graduate students, majoring at industrial design or visual communication design, from IAA and 3 graduate students from other departments of NCTU, majoring at architecture, computer engineering and management science, respectively. In order to encourage students breaking the wall cross between their professional fields, the lecturer of this course has prepared toys and tools, such as darts, light masking devices, buzzers, and various aids, to induce play. For the convenience of teaching, students are grouped as teams of two, and they would identify issues via cross-team discussions.

\section{The Proceeding of This Course}

In the aspect of scenarios, attention is paid onto the experience of amusement; through observing the set designs and scenarios in sci-fi movies, participants are stimulated to think on how to prepare for and respond to the dilemmas and challenges humanity may face in the ever-changing world of the future in advance. Because sci-fi stories usually contain imaginations and worries of the future, entangled with expectations of technology progress and fear of the unknown, designers, inspired by sci-fi stories, may conceive a sense of excitement and imaginations differ from the usual product scenarios and come up with interesting metaphors and reflections. Through the scenario stimulations from play, games, and movie plots, it is hoped to inspire the potentials in students to explore new problems. After the course outline is introduced, this course started in the form of gaming directly in the following week. We are proposed three steps that were: Warm up for pleasure, 3D model to test and Draw $\&$ Shared with others. The proceeding of this course includes the following six units:

Unit-1. Discuss the concept of scoring through the game of darts: created some steps to awaken the motivation for design practice. For example, we using magnetic darts and a 3D Iron Man image as the target, different parts of the target have different points ( 0 lowest, 100 highest),the students are divided into 6 teams of twos to play, as shown in Fig.2-a, and the team with the highest score wins. This is done to seduce the students in increasing their shooting precision to generate a sense of fun.

Unit-2. Blocking boxes + making light masking devices: Without identifying the purpose, each student is asked to prepare 5 empty boxes and bring them to the class next week. In the following week, the lecturer arranges the prepared light masking device and alarm (with sound and light) on the 
table, connects them to power and asks two students to construct a device from 10 boxes (as Fig.2-b). A foam-thrower is used as a shooting weapon for the boxes. Points are awarded if the fallen or displaced boxes block the light masking device and trigger an alarm sound, and the team with the highest score wins.

Unit-3. Movie analysis: By analyzing the concept of time and background of Sci-Fi movies, students are asked to discuss how the characters should react in the given scenario, and how the characters utilize sets and the environment to overcome the challenges in the mission. Stories imaginations are usually projections of reality; therefore, the designers can also seek out design topics via "virtuereality scenarios," look at the world through a contracted or enlarged scale, and create dramatic spatial effects. Designers can directly transform information drawn from reality into imaginary scenarios, and reflect upon statuses, behaviors, operating procedures hidden in real life, or plots in the movie, while also reveal the psychological demands in current products to stimulate imagination, relieve pressure, and provide relaxation for users.

Unit-4. Story telling + box Refining: Trough the method of reading comics, students are asked to construct a series of scenario introductions and interactive character dialogues (as Fig.2-c), then based on the thoughts of interactions to reconstruct boxes from above into a device with a variable mechanism to reflect the weight and movement of the bullets thrown (show as Fig.2-d, e).

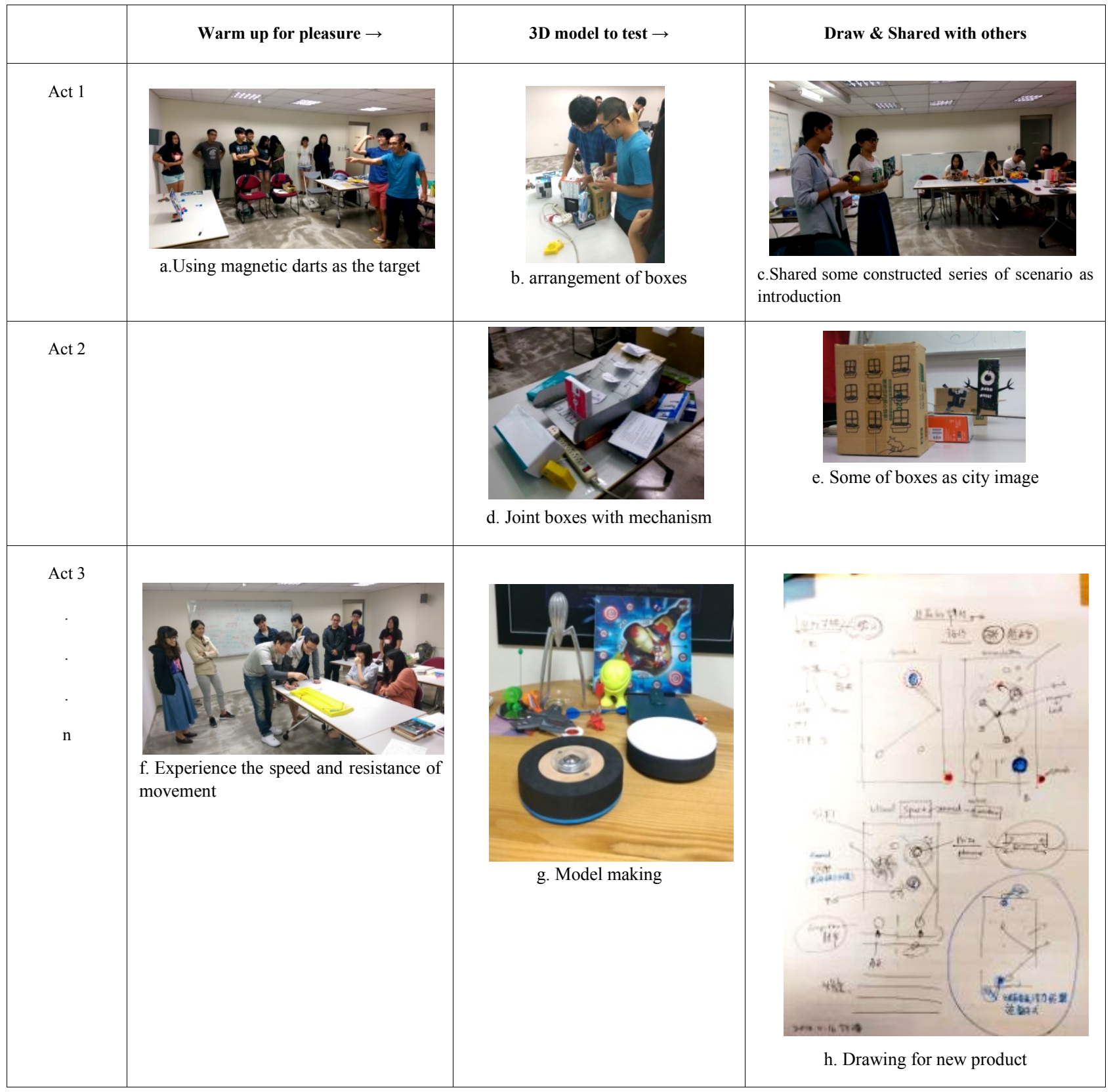

Figure 2. the steps to awaken the motivation for design practice 
Unit-5. Investigating the phenomenon of resistance and play: Through the observation of the play, the students experience the speed and resistance of movement of objects (as Fig. 2-f). Then, they are asked to summarize the process of the above units into topics for further development. The following topics are summarized and presented by the teams:

- Issue of stealth (cloak) and uncloak (spatial illusions, storage and opening, fun that may or may not be seen in life).

- Application experiments on methods of $3 \mathrm{D}$ vision and3 $\mathrm{D}$ fabrication.

- Issue of Later Wow (feeling generated by delayed visuals, proposed by Fukasawa Naoto). Experience messages left by a past person, event, or object.

- Enlargement plan (fun and scary) like ALESSI's Alien (reconstructed story scenario).

- Creation of Sci-Fi scenarios (possible forms and functions of thinking environment, spatial environment, characters, transportations, and weapons).

Unit-6. Team members cosplay their imaginary futuristic characters, and develop new products (Fig.2-g, h), accordingly.

\section{Initial Response to Course and Thoughts on Play-modes}

During the course of Play, Sci-Fi \& Design, the students first-handedly participated in the toy-operations, interactions, and analyses in the psychological level of play and sci-fi movies...etc. These experiences allow us to understand a simple game was actually hidden with a variety of interactive conditions, and game designs based on interactive psychology. Designing a game may require an seductive story introduction, and a fun, innovative, competitive game play to suck the players into the game world to be rewarded with an extreme satisfaction (reward) or disappointment (punish) to engage the players into retrying the challenge or competition again. Some simple rules may be extremely difficult when applied to the actual game play itself, because games are usually played from the user's angle, and now the psychological emotions triggered in the users while playing have to be speculated. How to precisely grasp the hearts of the users? These are important goals in designs and observations. (By Jacky Liu)

In addition, engaging in further thinking on scenario, stimulation, and social activity, the students have provided some initial game concepts, and the summaries are as follow.

\subsection{Concept of Game (1)}

A game that utilizes user-create monsters as the element of attraction. All users use the same initial monster model to start the game, after dueling other players, the winner can take a weapon, equipment, or physical characteristic from the defeated player. With every item retrieved, the change is reflected in the physical appearance of the player-monster (also changes in attack and defense attributes), and after accomplishing a mission objective in every stage, the actual monster model could be obtained by the player via methods of physical stores or 3D Printing as a reward for the efforts. (as Fig.3, concept designed by Jacky Liu)

Scenario: fighting with different monsters

Stimulant: winning or losing in fights. After each fight, the appearance of the monster changes toward the player's ideal image.

3D printing: When the monster reaches an appearance favored by the player, he can obtain it via 3D printing to fulfill the user's desire for collecting.

Social activity: communicate with different users, collect different monster models; maybe a periodic monster beauty contest will be held.

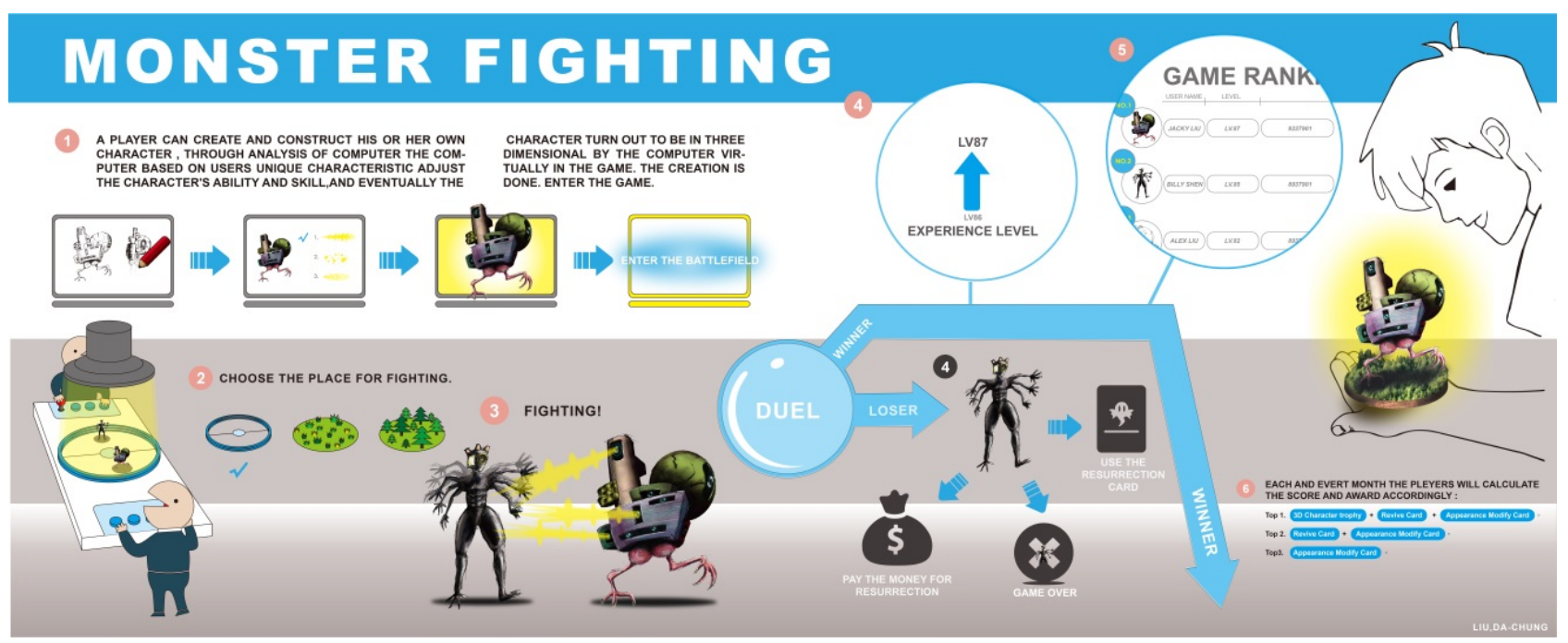

Figure 3. Scenario for The monster fighting process with award of 3D printing figure. (Designed by Jacky Liu) 


\subsection{Concept of Game (2)}

In correspondence to the alien designed by the gamer, a simple mask is selected to represent the self. Every mask has a slot to insert a mobile phone, and the gyro system inside the phone is used to engage the game (interactive game: the magnitude of head-turning controls the turning of the rotary table inside the game), and some scoring mechanism and game play are defined accordingly. (By student: Ke-Jyun Wu)

Scenario: alien duel.

Stimulant: competitiveness, view-turning, and other uncontrollable factors.

3D printing: print a medal or some representative reward.

Social activity: thoughts derived from experience, and they can be shared via internet.

\section{Conclusions}

The function and performance of the product must also consider the psychological effects. In order for a product to be able to move others, psychological or sensational factors users cared about must be integrated in design to create emotional attractions for affecting users unconsciously. In the practical aspect of designs, idea conceiving is an inspiration that requires active or passive stimulations to arouse the designer's inner mind for generating new sensations. If the stimulants that incorporate play can be induced systematically during the idea conceiving stage of design, creativity may be better inspired and a more interesting amusement effect may be obtained. It would helpful to arouse student's curiosity of thinking and creativity merged with experience for video game, table game, toy and product through play and competition. Therefore, the choice of the course topic becomes crucial, and lecturers must consider both the current and future design trend to design the course topics. In between every term and school year, the faculty may explore and discuss new course to pics for prospective products, such as interactive technology applications, behavior and situation of interactive system design, cross-platform gaming experience sharing...etc, and the resources may be gradually integrated in accordance to the direction of the prospective topics. This study is still proceeding, and the effect of the course will be tracked and examined once the course has been fully implemented.

\section{REFERENCES}

[1] Battarbee, K. (2001). Design for user experience. Helsinki, University of Art and Design Helsinki UIAH.

[2] Benyon, D. \& Turner, S. (2005). Designing interactive systems: People, activities, contexts, technologies. London: Pearson Education.

[3] Brown, T. (2009). Change by Design: How design thinking transforms organizations and inspires innovation. USA: Fletcher \& Company.

[4] Bruce \& Bessant (2002). Design in Business: Strategic Innovation Through Design. London: Pearson Education.

[5] Innocent, T. (2004). Designing Trans mutational World in Game Space. FUTUREGROUND: Design Research Cociety International Conference 2004. Monash University, Australia.

[6] Kohtala, C. \& Bosque, C. (2014). The Story of MIT-Fablab Norway: Community Embedding of Peer Production. Journal of Peer Production. http:// peerproduction.net.

[7] Norman, D. (2004). Emotional design: Why we love (or hate) everyday things. New York: Basic Books.

[8] Posch, I. \& Fitzpatrick, G. (2012). First Steps in the FabLab: Experiences Engaging Children. OZCHI' 12, Victoria, Australia.

[9] Rodgers, P. \& Milton, A. (2011). Product design. London: Laurence King Publishing.

[10] Suri, F. \& Marsh, M. (2000). Scenario building as an ergonomics method in consumer product design. Applied Ergonomics 31.151 157.

[11] Tanaka, Hiroya (2012). Fab Life. O’Reilly Japan, Inc. 